\section{CPS-268 EVALUATION OF THE SATISFACTION OF THE IMPLEMENTATION OF A PHARMACEUTICAL LETTER OF HOSPITAL DISCHARGE TRANSMITTED TO PATIENTS AND COMMUNITY HEALTH PROFESSIONALS}

1] Salgues*, 'L Viault, 'M Cosson, 'L Lohan-Descamps, 'D Rosant, "I Roch-Torreilles, ${ }^{1} \mathrm{M}$ Villiet, ${ }^{2} \mathrm{R}$ Goulabchand, ${ }^{3} \mathrm{P}$ Fesler, ${ }^{2} \mathrm{~A}$ Le Quellec, ${ }^{1} \mathrm{C}$ Breuker. ${ }^{1}$ University Hospital Centre of Montpellier, Pharmacy Unit, Montpellier, France; ${ }^{2}$ University Hospital Centre of Montpellier, Internal Medicine Unit Saint Eloi, Montpellier, France; ${ }^{3}$ University Hospital Centre of Montpellier, Internal Medicine Unit Lapeyronie, Montpellier, France

10.1136/ejhpharm-2019-eahpconf.417

Background The development of the activities of medication conciliation (CM) at admission and discharge have reduced medication errors. Due to the lack of time and adequate tools, CM information is rarely transmitted to patients or community health professionals (CHP). In our hospital, since July 2017, a pharmaceutical letter (PL) of hospital discharge is edited from CM data and integrated into the patient's computerised record. This PL is given and explained to the patient and transmitted to CHP (general practioner (GP), pharmacist, rehabilitation centre).

Purpose The objective of this study was to assess the satisfaction of PL transmission to CHP and patients.

Material and methods We conducted this prospective study in two internal medicine units from July 2017 to February 2017. This study using data regarding two internal medicine units (44 beds) were collected from July 2017 to February 2018. The PL and a satisfaction questionnaire were explained and given to the patient, and sent (email, regular mail or fax) to the pharmacy, the GP and/or the medical centre. The questionnaire included 10 questions, satisfaction scales from 0 (not at all satisfied) to 10 (very satisfied).

Results Two-hundred and six patients were included: sex ratio $\mathrm{M} / \mathrm{F}=0.6$, mean age 72 years' old and average length of stay of 13 days. Respectively 112 (54\%), 112 (54\%), 143 $(69 \%)$ and 66 (32\%) PL were given and explained to patients, sent to pharmacies, doctors and others health centres. The response rates for the questionnaires were respectively 53\% (59) for patients, 39\% (44) for pharmacies, $5 \%$ (seven) for GP and 9\% (seven) for others centres. Overall satisfaction was $8.6 \pm 2.1$ for patients, 9.3 \pm 0.9 for pharmacies, $8.2 \pm 2.3$ for GPs and $8.7 \pm 1.7$ for other centres. According to the patients, the explanations of PL significantly improved the knowledge of their treatments $(7.9 \pm 2.3$ versus $9.7 \pm 0.9, \mathrm{p}<0.001)$. Concerning sending modalities, the satisfactions were respectively $9.3 \pm 1.1,6.7 \pm 3.9$ and $9 \pm 1.3$ for pharmacies, GPs and other centres. Satisfaction concerning quality of information were respectively $9.5 \pm 0.8,9.2 \pm 1.2$, $7.3 \pm 2$ and $8.5 \pm 1.4$ for patients, pharmacists, GPs and other centres.

Conclusion According to these results, we observed a very positive overall satisfaction, on the one hand of patients, and on the other, of CHP.

\section{REFERENCES AND/OR ACKNOWLEDGEMENTS}

https://www.ncbi.nlm.nih.gov/pubmed/28007439

No conflict of interest.

\section{CPS-269 ARE PATIENTS AND HEALTHCARE PROFESSIONALS WILLING TO EXCHANGE THE PRICE OF TREATMENTS TO CHOOSE A BIOSIMILAR? EXPERIENCE BASED ON THE DELPHI METHOD}

${ }^{1} \mathrm{C}$ Gary, ${ }^{2} \mathrm{~A}$ Schiavon De Jodar*, ${ }^{2} \mathrm{~T}$ Deljehier, ${ }^{2} \mathrm{~F}$ Xuereb, ${ }^{3} \mathrm{~K}$ Bouabdallah, ${ }^{3} \mathrm{~A}$ Pigneux, ${ }^{3} \mathrm{~N}$ Milpied, ${ }^{2} \mathrm{D}$ Breilh. 'University Hospital of Bordeaux, Pharmacy and Haematology, Pessac, France; ${ }^{2}$ University Hospital of Bordeaux, Pharmacy, Pessac, France; ${ }^{3}$ University Hospital of Bordeaux, Haematology, Pessac, France

\subsection{6/ejhpharm-2019-eahpconf.418}

Background Health policies require improving the efficiency of healthcare by supporting the development of biosimilar drugs. French policies request that appropriate information should be given to patients who receive a biosimilar. According to an international study, only $6 \%$ of the general population is aware of what is a biosimilar. This data suggests that appropriate information about biosimilar is complicated and time-consuming. Few data are published on patients' opinions concerning cost and biosimilar drugs.

Purpose We aimed to establish a consensus on the important information that should be given to patients during an initial consultation, and to define to what extent we can discuss cost and biosimilar choice.

Material and methods This study was conducted in the department of haematology, a panel of 72 'experts' consisting of 50 patients and 22 healthcare professionals (HCP). The DELPHI method allowed the collection of the experts' opinions in a prospective way. We defined 12 items to be assessed in two rounds: one, choosing information useful to know; and two, prioritising essential information. In the third round, after correct explanations about biosimilars, experts were given a choice: accept or reject the biosimilar drug with detailed arguments.

Results First, experts assessed: 'cost of treatment', 'biosimilar/generic drug' useful to know up to $45 \%$ (patients: $63 \%$, HCP: $38 \%$ ) and 43\% (patients: 57\%, HCP: 38\%), respectively. The following items: 'side effects (SE)' and 'food/ drug prohibited' were selected as useful to know by $100 \%$ of the experts. Then, 'correct conduct in case of SE', 'SE' and 'intake modalities' were considered essential by the experts. Unexpectedly, 'cost' was mentioned by only $7 \%$ of the patients. At the third round, $55 \%$ of the patients accepted the biosimilar, 40\% did not decide and trusted in their HCP's decision and one patient rejected a biosimilar even when not convinced by HCP. Among HCP, 93\% accepted a biosimilar and only one HCP refused it. The main argument for choosing a biosimilar drug was 'economic reason'.

Conclusion These results suggest that patients and HCP are aware of the increasing cost of the drugs and the economic impact on society. Most patients trust their HCP in the choice of the most efficient therapy. Further investigations are needed to confirm these results, with a larger cohort of patients.

\section{REFERENCES AND/OR ACKNOWLEDGEMENTS}

No conflict of interest. 